\title{
MATERIAIS DIDÁTICOS DE PORTUGUÊS PARA ESTRANGEIROS COMO OBJETOS DE PESQUISA*
}

\author{
Pedagogical materials of Portuguese to speakers of other languages as research \\ objects
}

\author{
Maria Elaine MENDES ${ }^{1}$ \\ Wagner Rodrigues SILVA ${ }^{2}$
}

\begin{abstract}
Resumo: Apresentamos uma análise comparativa de pesquisas acadêmicas sobre materiais didáticos para ensino de português como língua adicional. Focalizamos mais diretamente os seguintes aspectos investigativos: justificativa; objetivo; dados; procedimento metodológico; e resultado. Os trabalhos selecionados foram motivados por dois principais interesses: práticos, caracterizados pela produção de contribuições para a elaboração e o uso do material didático; e teóricos, caracterizados pelo discernimento da apropriação de teorias linguísticas no referido material. Este artigo se configura como referência para professores e pesquisadores atuantes no ensino de português para falantes de outras línguas.
\end{abstract}

Palavras-chave: Ensino de Língua; Livros Didáticos; Métodos de Pesquisa.

Abstract: We present a comparative analysis of academic research on pedagogical materials for teaching Portuguese as an additional language. The researchers focus more directly on the following investigative aspects: pertinence; objective; data; methodological procedure; and result. The selected papers were motivated by two main interests: practical, characterized by the production of the contributions for the elaboration and use of pedagogical material; and theoretical, characterized by the perception of the appropriation of linguistic theories in the mentioned material. This article is a reference for teachers and researchers working on the teaching of Portuguese to speakers of other languages.

Keywords: Language Teaching; Textbooks; Research Methods.

\footnotetext{
* Este artigo faz parte das investigações de doutorado e pós-doutorado dos respectivos autores, desenvolvidas em estágio de ensino e pesquisa no Departamento de Língua Portuguesa, na Universidade de Aswan, Egito. Contribui para o grupo de pesquisa Práticas de Linguagens - PLES (CNPq/UFT).

${ }^{1}$ Doutoranda em Letras: Ensino de Língua e Literatura, pela Universidade Federal do Tocantins (UFT) e docente do Instituto Federal Goiano (IFGoiano). maria.mendes@ifgoiano.edu.br

${ }^{2}$ Doutor em Linguística Aplicada, docente da Universidade Federal do Tocantins (UFT), Câmpus de Palmas, e Bolsista de Produtividade do CNPq. wagnerodriguesilva@gmail.com
} 


\section{INTRODUÇÃO}

As pesquisas brasileiras sobre ensino de português como língua adicional (PLA) se configuram como uma área de investigação recente na Linguística Aplicada, até porque as políticas linguísticas brasileiras para propagação do português além das fronteiras do Brasil ainda são incipientes (cf. ALMEIDA FILHO, 1992; CARVALHO, 2012; DINIZ, 2012; OLIVEIRA, 2013; SILVA; ELGEBALY e MEDEIROS, 2017). Desta forma, este artigo mostra uma análise crítica de pesquisas na referida área, configurando-se como um trabalho de referência para pesquisadores e professores de PLA.

Apresentamos uma síntese de pesquisas sobre materiais didáticos (MD) para o ensino de PLA. Também realizamos uma análise comparativa de oito dissertações de mestrado acadêmico e uma tese de doutorado, nas quais MD, dentre os quais destacamos os livros didáticos (LD), foram construídos como objeto de pesquisa por diferentes perspectivas teórico-metodológicas. Além disso, focalizamos mais diretamente os seguintes aspectos das pesquisas selecionadas: justificativa; objetivo; dados; procedimento metodológico; e resultado.

A seleção dos referidos trabalhos acadêmicos foi realizada a partir de buscas na Internet, considerando como critério de seleção o enfoque de aspectos culturais nas investigações sobre os LD para o ensino de PLA. Inicialmente, consideramos os mestrados acadêmicos e doutorados que supomos terem maior tradição em pesquisa sobre ensino de língua, especialmente nos denominados Programas de Pós-Graduação em Linguística Aplicada, a exemplo dos ofertados na Universidade de Brasília (UNB) e na Universidade Estadual de Campinas (Unicamp). Posteriormente, consideramos trabalhos produzidos em programas com outras denominações, localizados nas Regiões Nordeste, Sudeste e Sul, conforme foram aparecendo nas pesquisas realizadas em sites de busca.

Durante a seleção dos trabalhos de mestrado e doutorado, encontramos a dissertação elaborada por Cuicui (2012) no contexto acadêmico de Portugal, a qual foi considerada nesta investigação, haja vista a relevância do estudo sobre MD para o ensino de PLA em universidades chinesas. Os LD investigados nos trabalhos selecionados foram elencados no Quadro 1. 
QUADRO 1: Livros didáticos analisados em dissertações e tese

\section{LIVROS DIDÁTICOS DE PLA}

ALMEIDA, A.; BARBOSA, C. N. Horizontes: rumo à proficiência em língua portuguesa. Buenos Aires: LiBreAr, 2010.

LAROCA, M. N. de C.; BARA, N.; CUNHA, S. M. Aprendendo Português do Brasil: um curso para estrangeiros. Pontes, 2003.

LIMA, E. E. O. F. Avenida Brasil. Curso básico de português para estrangeiros. Vol. 1 e $2.13^{a}$ ed. São Paulo: E.P.U., 2009.

LIMA, E. E. O. F; IUNES, S. A. Falar... ler... escrever... português: um curso para estrangeiros. São Paulo: E.P.U., 2013.

LIMA, E. E. O. F.; IUNES S. A. Português via Brasil: Um curso avançado para estrangeiros. São Paulo: EPU, 2005

LIMA, E. E. O. F.; IUNES, S. A.; LEITE, M. R. Diálogo Brasil: curso intensivo de português para estrangeiros. São Paulo: EPU, 2003.

LIMA, E. E. O. F.; IUNES, S. A. Falando, Lendo, Escrevendo Português: um curso para estrangeiros. EPU, 1994.

MOREIRA, A., BARBOSA, C. N., CASTRO, G. N. Brasil Intercultural (BI): língua e cultura brasileira para estrangeiros: ciclo básico (Níveis 1 e 2). Buenos Aires: Casa do Brasil, 2013.

PATROCÍNIO, E. F.; COUDRY, P. Fala Brasil: Português para estrangeiros. Pontes: Campinas, 2004.

PATROCÍNIO, E. F.; COUDRY, P. Sempre Amigos: português para Estrangeiros. Campinas: Pontes, 2000.

PONCE, M. H.; BURIM, S. A.; FLORISSE, S. Bem vindo! A língua portuguesa no mundo da comunicação. São Paulo: SBS, 2004.

PONCE, M. H. O.; BURIM, S. R. B. A.; FLORISSI, S. Tudo bem? Português para uma nova geração. São Paulo: SBS, 2001.

\section{DISSERTAÇÃO/TESE}

GONZÁLEZ (2015)

MENDES

STERNFELD

RICARDI (2005)

GONZÁLEZ

ROSA

(2015)

STERNFELD

VAZ (2013)

MENDES (2006)

ROSA (2015)

CASTRO (2009)

VAZ (2013)

CASTRO (2009)

STERNFELD (1996)

GONZÁLEZ (2015)

GONZÁLEZ

(2015)

STERNFELD (1996)

PACHECO

(2006) RICARDI (2005)

CASTRO

(2009)

RICARDI (2005)

PACHECO STERFELD (1996) 
As dissertações e tese foram agrupadas em três categorias analíticas, conforme o recorte investigativo do objeto de pesquisa construído, a saber: (1) Escolha e elaboração de materiais didáticos; (2) Abordagem de ensino assumida no livro didático; (3) Contribuição dos estudos da linguagem. Essas categorias identificam as três principais seções que compõem este artigo, além desta Introdução, das Considerações finais, da Lista de dissertações e tese analisadas e das Referências.

\section{Escolha e elaboração de materiais didáticos}

As pesquisas do Quadro 2 focalizam critérios de escolha e de elaboração de LD ou materiais com função semelhante, produzido e testado pelas próprias autoras da pesquisa. Os dois primeiros trabalhos apresentados se restringem ao ensino de LP para aprendizes com nacionalidades específicas.

QUADRO 2: Escolha e elaboração de materiais didáticos

\begin{tabular}{|l|l|l|}
\hline OBJETIVO & METODOLOGIA & RESULTADO
\end{tabular}

Dissertação 01: “A seleção e a produção de materiais didáticos no processo do ensino do português aos alunos chineses" (CUICUI, 2012).

\begin{tabular}{|c|c|c|}
\hline $\begin{array}{l}\text { "Verificar quais os critérios } \\
\text { para a seleção e para a } \\
\text { produção de materiais } \\
\text { didáticos em português, } \\
\text { principalmente os } \\
\text { materiais direcionados a } \\
\text { alunos chineses que } \\
\text { frequentam o curso de } \\
\text { licenciatura em português } \\
\text { nas universidades" (p. 6). }\end{array}$ & $\begin{array}{l}\text { Questionários mistos } \\
\text { (questões fechadas e } \\
\text { abertas) preenchidos pelos } \\
\text { próprios professores e } \\
\text { alunos das universidades } \\
\text { na China e em Portugal. } \\
\text { Este último país } \\
\text { corresponde ao local onde } \\
\text { foi produzida a dissertação. }\end{array}$ & $\begin{array}{l}\text { "A prática do professor de } \\
\text { português para a seleção e } \\
\text { produção do MD no ensino } \\
\text { de português a alunos } \\
\text { chineses tem sido } \\
\text { determinada, em grande } \\
\text { parte, pelos critérios sob a } \\
\text { influência da Abordagem } \\
\text { Comunicativa" (p. 51). }\end{array}$ \\
\hline \multicolumn{3}{|c|}{$\begin{array}{l}\text { Dissertação 02: "Tintim por tintim: um material didático de português para falantes de } \\
\text { espanhol com foco nas expressões idiomáticas" (VAZ, 2013). }\end{array}$} \\
\hline $\begin{array}{l}\text { "Elaborar e implementar } \\
\text { um material de base } \\
\text { comunicativa e abordagem } \\
\text { intercultural, que tem como } \\
\text { principal objetivo o ensino }\end{array}$ & $\begin{array}{lr}\text { Questionários } & \text { mistos } \\
\text { respondidos } & \text { pelos } \\
\text { professores } & \text { e } \text { aprendizes; } \\
\text { registros feitos } & \text { pelos } \\
\text { professores } & \text { em diários; }\end{array}$ & $\begin{array}{l}\text { "O material proporcionou } \\
\text { de maneira satisfatória o } \\
\text { ensino/ aprendizagem das } \\
\text { expressões idiomáticas, o } \\
\text { desenvol-vimento da }\end{array}$ \\
\hline
\end{tabular}




\begin{tabular}{|c|c|c|}
\hline $\begin{array}{l}\text { de expressões idiomáticas a } \\
\text { partir do uso da língua, } \\
\text { explorando aspectos } \\
\text { culturais brasileiros" (p. } \\
\text { 49). }\end{array}$ & $\begin{array}{l}\text { gravações em áudio das } \\
\text { aulas; impressões dos } \\
\text { aprendizes divulgadas, ao } \\
\text { final de cada aula, em um } \\
\text { blog. }\end{array}$ & $\begin{array}{l}\text { oralidade, o uso de uma } \\
\text { grande variedade de } \\
\text { amostras de registros da } \\
\text { língua portuguesa e a } \\
\text { difusão e aquisição da } \\
\text { língua-cultura alvo" (p. } \\
\text { 94). }\end{array}$ \\
\hline \multicolumn{3}{|c|}{$\begin{array}{l}\text { Dissertação 03: “Aprender português-língua estrangeira em ambiente de estudos sobre } \\
\text { o Brasil: a produção de um material” (STERNFELD, 1996). }\end{array}$} \\
\hline $\begin{array}{l}\text { "Produzir um material que } \\
\text { trouxesse informações } \\
\text { sobre o Brasil e gerasse } \\
\text { para os participantes do } \\
\text { processo de sala de aula } \\
\text { uma experiência } \\
\text { intercultural e de língua em } \\
\text { uso, fundamentada } \\
\text { teoricamente } \\
\text { abordagens } \\
\text { comunicativas" (p. 9). }\end{array}$ & $\begin{array}{l}\text { Questionários } \\
\text { respondidos mistos } \\
\text { aprendizes; registros feitos } \\
\text { pelos professores e pelos } \\
\text { alunos em diários; } \\
\text { gravações em áudio e vídeo } \\
\text { das aulas; entrevistas } \\
\text { coletivas com os } \\
\text { aprendizes, gravadas em } \\
\text { áudio. }\end{array}$ & $\begin{array}{l}\text { "O material, dentro de uma } \\
\text { abordagem comunicativa, } \\
\text { possibilitou o desenvolvi- } \\
\text { mento da competência lin- } \\
\text { guística e comunicativa dos } \\
\text { aprendizes através de } \\
\text { ativida-des interativas, } \\
\text { promovendo } \\
\text { comunicação intercultural } \\
\text { com as informações } \\
\text { fornecidas sobre aspectos } \\
\text { do Brasil". }\end{array}$ \\
\hline
\end{tabular}

A pesquisa de Cuicui (2012) focaliza o contexto universitário chinês. Para justificar o trabalho, a autora afirmou que o estudo do ensino de PLA na China, principalmente relacionado à produção e utilização dos MD, ainda apresenta lacunas. Em comparação com a quantidade e variedade de materiais para ensino de língua no referido país, é constatado um baixo número de MD na área do ensino de PLA para chineses. A autora salientou a necessidade de utilização de recursos adequados aos objetivos a que o ensino é proposto, garantindo a aprendizagem da LP e da sua cultura. Ressaltou ainda o desconhecimento dos critérios utilizados pelos professores para a seleção e a produção de seus próprios materiais.

A pesquisa de Vaz (2013) foi direcionada aos aprendizes falantes nativos de espanhol (venezuelano, dominicano, peruano, colombiano, espanhol, mexicano e argentino). Apesar de compartilharem a mesma língua, a variedade de nações foi importante para que diferentes aspectos culturais fossem encontrados. O objeto de pesquisa foi definido a partir de questões relatadas pelos aprendizes de português, ao explicitarem que, em um determinado momento do processo de aprendizagem, começaram a misturar palavras do português e do espanhol. Também descreveram situações de constrangimento e mal-entendidos, vivenciadas por eles devido à mistura 
lexical. A autora relatou ter percebido que as expressões idiomáticas (EI), unidades fraseológicas que expressam aspectos culturais característicos de uma comunidade de falantes, não eram trabalhadas de maneira satisfatória nos LD de PLA e que o aprendiz pode não ter elementos linguísticos e culturais suficientes para decodificar o sentido e analisar o contexto de uso de tais unidades fraseológicas.

A pesquisa de Sternfeld (1996) envolveu um grupo misto de dez nacionalidades (peruana, venezuelana, colombiana, argentina, sueca, iugoslava, francesa, coreana, russa e japonesa). Como justificativa do estudo, a autora apontou que o paradigma gramatical no ensino de PLA esteve vigente por muito tempo e que, aparentemente, uma das maiores dificuldades que professores enfrentam para mudar a sua prática e, consequentemente, possibilitar novos meios de aprendizagem, está relacionada à alteração de tal paradigma, incluindo, assim, novos requisitos que abrangem outras competências necessárias ao ato comunicativo, como a competência sociolinguística-cultural, a estratégica e a discursiva. Ainda, segundo a autora, esses aspectos obrigam, muitas vezes, o professor a ter que lidar com questões linguísticas e culturais imprevisíveis e, com isso, o foco da aprendizagem deixa de estar apenas na língua, para também se trabalhar o estudo de outros conhecimentos e a informação na própria cultura do aluno e na cultura-alvo.

Os três trabalhos focalizados desenvolveram a análise baseada nas reflexões dos professores ou dos aprendizes, expressas em questionários com questões abertas e fechadas. Nas pesquisas de Vaz (2013) e Sternfeld (1996), os questionários serviram como base para a avaliação dos MD elaborados. No estudo desenvolvido por Cuicui (2012), os questionários foram utilizados para descobrir os critérios que os professores utilizaram para seleção e produção dos materiais.

O trabalho de Cuicui (2012) foi desenvolvido utilizando procedimentos característicos da abordagem quantitativa de pesquisa e fundamentado teoricamente na abordagem comunicativa de ensino. Os resultados estão atrelados, principalmente, ao questionário respondido pelos professores. As opções para adoção do LD, apresentadas no questionário, foram elaboradas a partir dos itens propostos por Bohn (1988). Os professores poderiam escolher todos os critérios que julgassem necessários, levando também em conta os critérios para a escolha do MD, conforme as premissas da abordagem comunicativa. A partir dos questionários, foram criadas categorias com base nos parâmetros da referida abordagem na aquisição da LP, em que se apresentavam as quatro competências específicas (falar, ouvir, escrever e ler). As categorias criadas foram: (1) "critérios mais utilizados para a seleção dos LD para o objetivo geral de ensino"; (2) 
“critérios diferentes para a seleção e produção de materiais didáticos para os objetivos específicos (diferentes disciplinas) no processo de ensino do português aos alunos chineses"; e (3) "situações reais da utilização do livro didático no processo de ensino do português aos alunos chineses em terra natal" (CUICUI, 2012, p. 6).

Nos trabalhos de Sternfeld (1996) e de Vaz (2013), a coleta de dados foi feita a partir da intervenção do material produzido em um curso para aprendizes estrangeiros da LP. As autoras atuaram como professoras regentes dos cursos e, ainda, foram convidados professores colaboradores que atuaram como observadores das aulas. Em cada trabalho, um desses professores também ministrou algumas aulas, com o objetivo de fornecer contribuições para a construção do material elaborado e utilizado no curso.

O MD foi construído por Vaz (2013) utilizando diferentes tipos de textos extraídos de jornais e revistas impressos e virtuais, além de músicas e vídeos. Os aspectos culturais foram o cerne da concepção do material e foram considerados na escolha dos temas de cada unidade, assim foi composto por quatro unidades organizadas em seções intituladas com objetivos específicos com uma EI relacionada a diferentes campos semânticos: Sem pé nem cabeça (partes do corpo); Tudo azul (cores); Batendo um bolão (futebol); e Cada macaco no seu galho (animais).

O MD elaborado por Sternfeld (1996) foi feito por meio da leitura de um compilado de textos, encontrados em pastas de recortes de jornais e revistas nacionais em algumas bibliotecas, referentes aos indígenas do Brasil e aos negros e, ainda, por meio de uma série de leituras e anotações bibliográficas de livros sobre a história da cultura brasileira.

Em Vaz (2013) e Sternfeld (1996), a análise dos dados foi feita, em um primeiro momento, a partir da avaliação dos materiais tomados como base para a elaboração do material usado no curso; posteriormente, foi realizada uma comparação dos registros dos professores colaboradores e das autoras dos trabalhos e das reflexões dos aprendizes apresentadas através das entrevistas ou questionários para verificar se havia concordância nas impressões e considerações sobre os cursos e os materiais e, assim, verificar se os objetivos pretendidos haviam sido alcançados. No trabalho de Sternfeld (1996), um historiador, um antropólogo, uma professora de gramática da LP e um professorpesquisador que utilizou o material em um curso regular apresentaram comentários sobre o material. Vaz (2013, p. 63) elaborou quatro categorias de análise: (1) "aspectos culturais - culturas brasileiras ou outras culturas"; (2) "escolha dos materiais insumo"; (3) "aspectos linguísticos do português”; e (4) "ensino de expressões idiomáticas". Diante 
das análises dos resultados a partir dos comentários expressos pelos aprendizes, professores, próprias autoras e demais colaboradores, Sternfeld (1996) e Vaz (2013) declararam aprovação do material elaborado.

Sternfeld (1996) e Vaz (2013) apresentaram alguns aspectos que, segundo as próprias autoras, justificaram as sugestões de novas pesquisas nas áreas relacionadas. Assim, Sternfeld (1996) analisou modificações que julgou necessárias no material, conforme ter percebido os seguintes problemas: (1) algumas atividades promoviam situações em que prevaleciam a metodologia individual da professora; (2) alguns enunciados das atividades deveriam ter sua linguagem simplificada; (3) deveriam ser feitas reformulações para maior apropriação de alguns enunciados; (4) algumas atividades requereram mudança, por exemplo, em uma atividade a palavra "correto" trazia uma marca crítica e preconceituosa; e (5) deveriam ser feitas reformulações quanto à apresentação da gramática no material.

Vaz (2013) percebeu que é muito fácil difundir estereótipos negativos, preconceitos e intolerâncias através dos conteúdos dos MD, destacou que as EI, por terem uma carga cultural muito forte em seu significado, têm um papel de destaque nessa situação. A autora apontou que sua pesquisa teve três limitações: (1) tempo, pois algumas atividades exigiram um tempo maior que o planejado, com isso uma das unidades elaboradas não chegou a ser utilizada; (2) pouca experiência em edição e diagramação, pois o material elaborado teve um aspecto visual que deixou a desejar; e (3) falta de materiais no mesmo modelo do que foi elaborado. Segundo a autora, caso já tivessem sido feitas outras pesquisas na área, o material elaborado poderia ter tido mais qualidade.

Cuicui (2012) apresentou como possíveis limitações da pesquisa a falta de professores portugueses com experiência na China e que a maior parte dos professores entrevistados eram profissionais novos com experiência pedagógica inferior a quatro anos; e a dificuldade para organizar as noções completamente diferentes dos professores que ensinam o português na China daqueles que ensinam em Portugal e as ideias dos professores chineses (tendo o chinês como língua materna) dos professores portugueses (tendo o português como língua materna). A autora, por fim, estabeleceu que a pesquisa demonstrou a necessidade de aprimoramento constante dos professores através de informações e debates referentes aos critérios para seleção/produção de um MD eficaz. 


\section{Abordagem de ensino assumida no livro didático}

No Quadro 3, esquematizamos três pesquisas a respeito de abordagens de ensino do PLA em LD. Em Mendes (2006), foram enfatizadas as atividades de compreensão e produção escrita; em Castro (2009), o enfoque investigativo foram os textos multimodais; em González (2015), foram investigados os traços característicos da abordagem das unidades e atividades didáticas, além de papéis implícitos de alunos e professores e conceitos implícitos de língua, linguagem, língua estrangeira e aprender e ensinar uma língua estrangeira.

QUADRO 3: Abordagem assumida no livro didático

\section{OBJETIVO}

METODOLOGIA

RESULTADO

Dissertação 04: "Análise de abordagem de material didático para o ensino de línguas (PLE/PL2)" (GONZÁLEZ, 2015).

\begin{tabular}{|c|c|c|}
\hline $\begin{array}{l}\text { PLE produzidos na } \\
\text { Argentina? Quais traços da } \\
\text { abordagem comunicativa e } \\
\text { quais da abordagem } \\
\text { gramatical esses materiais }\end{array}$ & $\begin{array}{l}\text { Dois volumes de materiais } \\
\text { didáticos de } \\
\text { produzidos na Argentina: } \\
\text { Brasil } \text { Intercultural: } \\
\text { Língua e } \text { Cultura } \\
\text { Brasileira } \\
\text { Estrangeiros - Ciclo básico } \\
\text { (Níveis 1 e 2); Horizontes: } \\
\text { rumo à proficiência em } \\
\text { língua portuguesa. }\end{array}$ & $\begin{array}{l}\text { "'Brasil Intercultural' é } \\
\text { pré-comunicativo com } \\
\text { forte presença da } \\
\text { abordagem gramatical e } \\
\text { alguns aspectos da } \\
\text { abordagem comunicativa" } \\
\text { (p.125). "Horizontes' é } \\
\text { predominantemente } \\
\text { comunicativo, porém } \\
\text { devido à forte presença de } \\
\text { atividades pré- } \\
\text { comunicativas, não pode } \\
\text { ser declarado totalmente } \\
\text { como uma abordagem } \\
\text { comunicativa" (p.127). }\end{array}$ \\
\hline
\end{tabular}

Dissertação 05: "A abordagem subjacente ao material didático de português língua estrangeira: a análise da multimodalidade textual" (CASTRO, 2009).

\begin{tabular}{|c|c|c|}
\hline ir a na & $\begin{array}{l}\text { Foram analisados três LD: } \\
\text { Diálogo Brasil - Curso } \\
\text { intensivo de português } \\
\text { para estrangeiros; } \\
\text { Português via Brasil: um } \\
\text { curso avançado para }\end{array}$ & $\begin{array}{l}\text { Diálogo Brasil, curso } \\
\text { intensivo de português } \\
\text { para estrangeiros } \mathrm{e} \\
\text { Português via Brasil: um } \\
\text { curso avançado para } \\
\text { estrangeiros remetem a }\end{array}$ \\
\hline
\end{tabular}


REVISTA X, Curitiba, volume 12, n.2,p.231-253,2017

\begin{tabular}{|c|c|c|}
\hline $\begin{array}{l}\text { universidades brasileiras" } \\
\text { (p. 6). }\end{array}$ & $\begin{array}{l}\text { estrangeiros; Bem-vindo! } \\
\text { A lingua portuguesa no } \\
\text { mundo da comunicação. }\end{array}$ & $\begin{array}{l}\text { uma } \text { abordagem } \\
\text { gramatical. Bem-Vindo! A } \\
\text { língua portuguesa no } \\
\text { mundo da comunicação } \\
\text { tem um caráter não } \\
\text { comunicativo, no máxi-mo } \\
\text { "comunicativizado". }\end{array}$ \\
\hline \multicolumn{3}{|c|}{$\begin{array}{l}\text { Dissertação 06: "Português língua estrangeira: uma análise do livro didático" } \\
\text { (MENDES, 2006). }\end{array}$} \\
\hline $\begin{array}{l}\text { "Analisar se as atividades } \\
\text { de compreensão e } \\
\text { produção escrita, em LD } \\
\text { voltados para o ensino de } \\
\text { PLE, propiciam ao } \\
\text { aprendiz as competências } \\
\text { de compreender e produzir } \\
\text { textos em língua } \\
\text { estrangeira" (p. 12). }\end{array}$ & $\begin{array}{l}\text { Dez livros didáticos (texto } \\
\text { e de exercícios) para ensino } \\
\text { de PLE, nos níveis } \\
\text { iniciante e intermediário: } \\
\text { Avenida Brasil: Curso } \\
\text { básico de Português para } \\
\text { estrangeiros (Volumes } 1 \mathrm{e} \\
\text { 2); Fala Brasil: português } \\
\text { para estrangeiros; Falar... } \\
\text { Ler... Escrever... } \\
\text { Português: um curso para } \\
\text { estrangeiros; Aprendendo } \\
\text { o português do Brasil: um } \\
\text { curso para estrangeiros. }\end{array}$ & $\begin{array}{l}\text { Os LD destacam as } \\
\text { atividades de compreensão } \\
\text { e produção escrita, porém, } \\
\text { elas são, na maioria dos } \\
\text { casos, descontextualizadas } \\
\text { e trabalhadas sem } \\
\text { articulação com outras } \\
\text { habilidades. }\end{array}$ \\
\hline
\end{tabular}

González (2015) justificou a pesquisa desenvolvida relatando que, na Linguística Aplicada, já havia, na década de 80, literatura referente à necessidade de o ensino de português para hispano falantes ser diferente do ensino de português para falantes de outras línguas. Dessa forma, a autora verificou se nos LD havia abordagens de base teórica diferente e algum tipo de apropriação da abordagem comunicativa. Ainda pretendeu configurar um procedimento de seleção de materiais didáticos, baseado em fundamentos teóricos e pressupostos da análise de abordagem.

Segundo Castro (2009), a distribuição e utilização de LD são processos bastante complexos, a análise do material é uma tarefa que requer atenção a diversos aspectos constitutivos. Com isso, elaborou uma análise focalizada principalmente nas capas, analisando também algumas páginas dos livros, a fim de ter uma noção de como os textos multimodais funcionam e como eles interagem na produção de significados, pretendendo, assim, ao final, responder aos seguintes questionamentos propostos: "1) como se pode ler 
a multimodalidade nas imagens no livro didático? 2) qual a relação das imagens com a abordagem comunicativa?" (CASTRO, 2009, p. 16).

Mendes (2006) analisou o espaço que as atividades de compreensão e produção escrita ocupam nos LD. Observou se essas atividades propiciam ao estudante as competências de compreender e produzir textos em outra língua, buscando, assim, verificar a noção de compreensão e produção escrita presentes nos LD. Investigou se as atividades propostas nos livros refletiam as concepções teóricas mais recentes, mais especificamente no que se refere à abordagem comunicativa, sobre o processo de ensinaraprender uma língua adicional. A autora expressou que o domínio da leitura não pode ser isolado das práticas linguísticas já que falar bem pode contribuir para a melhora da prática da escrita, a qual, por sua vez, pode auxiliar na ampliação das competências de leitura. $O$ indivíduo, além de aprender a escrever, desenvolve-se em termos de domínio da língua escrita, o que não dispensa a prática de leitura.

González (2015, p. 82-83) estabeleceu os seguintes critérios para seleção dos livros: (1) "o caso escolhido - a produção argentina de materiais didáticos para o ensino de PLA"; (2) "livros de produção independente - ambos os livros foram elaborados por professores e especialistas da área de PLA associados a duas instituições de ensino dessa língua na Argentina"; e (3) "abordagem comunicativa - em ambos os livros seus autores declaram haver utilizado os princípios da abordagem intercultural para a elaboração dos mesmos". Castro (2009, p. 59) selecionou os LD a partir de dois critérios básicos: (1) "o ano de publicação ou reedição, já que tinha como enfoque a análise de materiais recentes, publicados de acordo com as novas tecnologias"; e (2) "a forte presença de imagens, fotos e outros recursos que compunham o material". Já Mendes (2006, p. 34) escolheu os LD utilizados em sua pesquisa conforme os seguintes critérios: (1) "materiais voltados para o ensino de português como língua adicional"; (2) "livros que fossem utilizados de forma recorrente nos cursos de PLA"; e (3) "livros de PLA que fossem utilizados também fora do Brasil".

Os três autores assumiram uma mesma posição quanto às abordagens gramatical e comunicativa: em contraposição aos métodos gramaticais com foco na forma e desprivilegiando a interação, as atividades dentro de uma abordagem comunicativa têm foco no significado e promovem negociação e interação social para sua resolução. Castro (2009) ainda expôs que, além de não privilegiar a interação, a abordagem gramatical também não favorece as práticas sociais e culturais que estão submetidas as comunidades de fala da língua-alvo. A abordagem comunicativa transforma a sala de aula em realidade 
discursiva, já que permite ao aluno conhecer as práticas sociais inerentes à língua e cultura alvo, além de vivenciar a interação em sala de aula. Partindo do pressuposto de que a interação é fundamental para o domínio da língua-alvo, o autor afirmou que, a fim de se aproximar o ambiente de aprendizagem às situações naturais, é necessário focalizar a interação oral ou escrita em sala de aula. Além disso, evidenciou que a aprendizagem de outra língua, através da elaboração, seleção e utilização propícias do MD, deve estar concentrada no engajamento discursivo dos alunos, considerando o posicionamento na cultura, história e sociedade. Nesse sentido, Mendes (2006) apontou que a leitura é o produto da interação entre o texto e o leitor, quem convoca seus referenciais culturais constrói o sentido do texto.

Castro (2009) declarou que a linguagem recebe influências das práticas sociais que a permeiam e, em consequência de se observar uma tendência contemporânea de utilização de textos dos meios de comunicação, como jornais, revistas, internet, televisão, entre outros, isso tem refletido diretamente na elaboração do MD para ensino de línguas. Muitas vezes, este material é a primeira forma de contato que o aprendiz tem com a língua adicional e com a cultura da língua alvo. As formas imagéticas de representação visual estão cada vez mais presentes na sociedade e, desta forma, a escrita está deixando de ocupar o papel principal como representação cultural. Além de auxiliarem os alunos na formação de crenças e valores, os LD contêm representações sociais que fazem parte da identidade de um povo, de sua cultura, de suas práticas sociais e também do reforço ou não de estereótipos culturais, tornando, assim, o espaço onde se aprende outra língua um lugar repleto de representações de identidades e conflitos culturais. Nesse contexto, foi destacada a necessidade de o professor realizar um trabalho adequado com textos multimodais, já que estes são permeados por aspectos ideológicos que podem vir a ser naturalizados na fala do aluno.

Quanto aos livros que foram analisados, González (2015) pontuou que: na coleção Brasil Intercultural: língua e cultura brasileira para estrangeiros, a autora relatou que a Casa do Brasil ${ }^{3}$, visando atender às exigências e características avaliativas do exame

\footnotetext{
3 Conforme informado na página eletrônica da Casa Brasil, a instituição "foi fundada em 1990, transformando-se na primeira instituição privada especializada no ensino do Português como Língua Estrangeira (PLE) em Buenos Aires. Converteu-se, durante 25 anos de trabalho ensinando português e difundindo a cultura brasileira, em uma referência, tanto pela qualidade e variedade dos cursos que oferece como serviços que presta, dentre os quais se destacam a programação cultural, a Biblioteca Jorge Amado e a Livraria Casa do Brasil" (tradução nossa). Fonte: < http://www.casadobrasilar.com/nosotros > Acesso 07 jan. 2017.
} 
CELPE-BRAS e satisfazer as necessidades dos alunos e professores da própria e de outras instituições que manifestavam a conclusão de não se identificar mais com os livros que chegavam do Brasil, constatou a necessidade de produzir seu próprio MD. Para a codificação do novo material, foram identificadas as necessidades da abordagem intercultural, o conceito de língua em uso, a oferta de diversos gêneros textuais e a focalização do público hispano falante. Já sobre Horizontes: Rumo à proficiência em língua portuguesa, Gonzáles (2015) relatou que as autoras declararam ter elaborado os materiais a partir dos princípios da "abordagem intercultural".

Respondendo às perguntas de pesquisa, após a análise descritiva das características da abordagem dos LD selecionados, González (2015) chegou às seguintes conclusões: quanto ao livro Brasil Intercultural, apesar de ser caracterizado por seus autores como "abordagem intercultural”, González (2015, p. 125) identificou, através da sua análise, que o LD é "pré-comunicativo com forte presença da abordagem gramatical tendo, ainda, alguns aspectos da abordagem comunicativa". O mesmo ocorreu em relação ao LD Horizontes, que é caracterizado por sua autora como "abordagem intercultural" e, por outro lado, de acordo com sua análise, González (2015, p. 127) concluiu que é um livro "predominantemente comunicativo", porém, afirmou que devido à "forte presença de atividades pré-comunicativas, o MD não pode ser declarado totalmente como uma abordagem comunicativa".

Na pesquisa de Castro (2009), as análises conduziram aos seguintes resultados. Com relação à modalidade imagética nas capas dos $\mathrm{MD}$, o autor constatou que apesar da representação da mata retratar uma característica da identidade brasileira, a imagem presente na capa do livro não possibilita ao leitor fazer grandes associações. A presença de cores é quase nula e praticamente todo o livro é monocromático, com isso explicou que a ausência de cor é desmotivadora para a leitura de textos multimodais e, sendo as cores representativas do mundo, a cultura brasileira é conhecida pelas cores vibrantes que remetem ao tropicalismo, à pluralidade da sociedade e à alegria. Não foi possível identificar interação entre os participantes nem uma proposta de ação a partir da imagem representada na capa. Os livros selecionados são analisados comparativamente.

Castro (2009) inferiu que a multimodalidade é inerente à própria linguagem, sendo assim um fator determinante para que o aluno compreenda o conteúdo dos textos. Com os resultados, respondeu às duas questões propostas inicialmente da seguinte forma: (1) o autor considerou que a imagem relacionada à linguagem verbal e outras semioses proporcionam ao aprendiz estrangeiro um contexto comunicativo em que se pode 
conhecer a cultura brasileira através da multimodalidade; (2) quanto à relação das imagens com a abordagem comunicativa, o autor verificou que é "uma relação real, mas não é determinante, já que a utilização de imagens e cores não necessariamente compõe um contexto comunicativo" (p. 74). Ressaltou, ainda, que a comunicação plena é resultado das combinações das várias semioses, e, além disso, observou, com sua análise, que as capas são um prelúdio do restante do conteúdo dos LD.

Mendes (2006), na descrição que expôs dos LD, apresentada pelos próprios autores em cada material, citou os aspectos culturais considerados por cada material: (1) Fala Brasil: Português para estrangeiros, os autores ressaltaram a necessidade de destacar a presença da cultura brasileira em situações da vida diária e que isso, para os autores, evitava a utilização dos "aborrecidos textos informativos"; (2) Falar... Ler... Escrever... Português: um curso para estrangeiros, afirmaram que a cultura brasileira era transmitida através de textos narrativos que tratam de aspectos históricos e geográficos; (3) Aprendendo o Português do Brasil: um curso para estrangeiros, os autores explicaram que um dos múltiplos objetivos desse volume era informar ao aprendiz sobre a cultura popular do Brasil a partir de atividades variadas tanto no que se refere ao conteúdo quanto à forma; (4) Avenida Brasil, a autora não expôs, na descrição do material, nenhum aspecto cultural.

Os resultados obtidos foram discutidos por Mendes (2006), conforme os questionamentos levantados: (1) em geral, nos volumes analisados, as atividades de compreensão e produção escrita não estão em concordância com as novas concepções de ensino/aprendizagem de línguas estrangeiras; (2) os LD destacam as atividades de compreensão e produção escrita, porém, elas são, na maioria dos casos, descontextualizadas e trabalhadas sem articulação com outras habilidades; e (3) os resultados da análise de cada volume contrariam a postura, quanto à valorização da língua como uso, que os autores afirmam adotar nos LD.

Mendes (2006) concluiu que grande parte dos textos utilizados nos LD se distancia da abordagem comunicativa, ou seja, do uso social e interativo da língua para fins de aquisição. Portanto, no tocante ao tratamento dado à língua alvo nos LD, a autora nos permite compreender que os materiais são marcados por abordagens formais da língua, compreendendo principalmente a proposição de exercícios gramaticais mecânicos. Porém, ressaltou um ponto extremamente positivo dos volumes analisados: a preocupação com o ensino da cultura brasileira. 


\section{Contribuição dos estudos da linguagem}

Nesta última seção analítica, reunimos duas dissertações de mestrado e uma tese de doutorado em que os autores investigam, mais diretamente, contribuições dos estudos linguísticos apropriadas nos LD, a exemplo do trabalho com aspectos semânticos e sociolinguísticos da linguagem. O Quadro 4 apresenta a síntese analítica.

QUADRO 4: Contribuição dos estudos da linguagem

\section{OBJETIVO}

METODOLOGIA

\section{RESULTADO}

Dissertação 07: "O sentido construído pelo discurso no ensino de língua portuguesa como língua estrangeira" (ROSA, 2015).

\begin{tabular}{|c|c|c|}
\hline $\begin{array}{l}\text { "Verificar se os LD } \\
\text { preveem, em seus textos e } \\
\text { atividades, o envolvimento } \\
\text { da semântica dos } \\
\text { enunciados no processo de } \\
\text { ensino-aprendizagem do } \\
\text { estudante" (p. 12). }\end{array}$ & $\begin{array}{l}\text { Análise de dois discursos de } \\
\text { livros didáticos de PLE: "O } \\
\text { trabalho da mulher" em } \\
\text { Avenida Brasil: curso } \\
\text { básico de português para } \\
\text { estrangeiros (p. 83); "Usos } \\
\text { e costumes - Bahia, Ceará, } \\
\text { Rio Grande do Sul" em } \\
\text { Falar... ler... escrever... } \\
\text { Português: um curso para } \\
\text { estrangeiros (p. 95-06). }\end{array}$ & $\begin{array}{l}\text { "O trabalho da mulher" } \\
\text { contém, } \\
\text { predominantemente, } \\
\text { questões concentradas no } \\
\text { conteúdo, que não } \\
\text { possibilitam ao estudante a } \\
\text { compreensão semântica do } \\
\text { discurso. "Usos e costumes } \\
\text { - Bahia, Ceará, Rio Grande } \\
\text { do Sul" inclui questões que } \\
\text { não acrescentam à } \\
\text { interpretação do texto e } \\
\text { questões que não exigem a } \\
\text { compreensão do texto como } \\
\text { um todo. }\end{array}$ \\
\hline
\end{tabular}

Dissertação 08: "A diversidade linguística brasileira no material didático para o ensino de português para estrangeiros" (RICARDI, 2005).

\begin{tabular}{|c|c|c|}
\hline 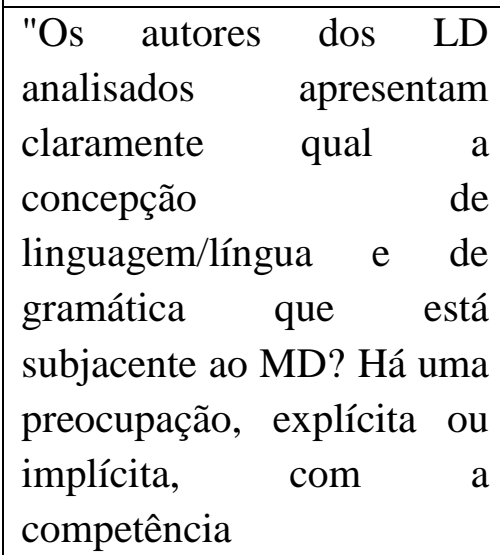 & $\begin{array}{l}\text { Aprendendo portuguê, } \\
\text { Brasil: um curso } \\
\text { estrangeiros; } \\
\text { amigos: Fala Brasil } \\
\text { jovens; } \quad \text { Bem-vindo! } \\
\text { língua }\end{array}$ & $\begin{array}{l}\text { amigos: fala Brasil } \\
\text { jovens, os mat } \\
\text { baseiam-se nas presc } \\
\text { de gramáticas norma } \\
\text { A compet } \\
\text { sociolinguística dos fa } \\
\text { não é contemplada } \\
\text { materiais, sendo abo }\end{array}$ \\
\hline
\end{tabular}




\begin{tabular}{|c|c|c|}
\hline $\begin{array}{l}\text { sociolinguística dos alunos? } \\
\text { Como se apresenta o quadro } \\
\text { pronominal nos manuais } \\
\text { didáticos de PLE? A } \\
\text { variação linguística no uso } \\
\text { pronominal está } \\
\text { comtemplada nos livros } \\
\text { didáticos?" (p.60). }\end{array}$ & $\begin{array}{l}\text { mundo da comunicação; } \\
\text { Tudo bem? português para } \\
\text { a nova geração (volume } 1 \mathrm{e} \\
\text { 2). }\end{array}$ & $\begin{array}{l}\text { comunicativa. Em geral, os } \\
\text { materiais apresentam as } \\
\text { inovações do paradigma } \\
\text { pronominal do português } \\
\text { brasileiro, porém com } \\
\text { exercícios artificiais e sem } \\
\text { relevância. Nos LD, a } \\
\text { variação no uso pronominal } \\
\text { não está contemplada. }\end{array}$ \\
\hline \multicolumn{3}{|c|}{$\begin{array}{l}\text { Tese 09: "Português para estrangeiros e os materiais didáticos um olhar discursivo" } \\
\text { (PACHECO, 2006). }\end{array}$} \\
\hline $\begin{array}{l}\text { "Identificar e discutir os } \\
\text { contratos de comunicação } \\
\text { (CC) em LD de PLA } \\
\text { dirigidos a adolescentes e os } \\
\text { efeitos da implementação } \\
\text { da abordagem comunicativa } \\
\text { de ensino" (p. 5). }\end{array}$ & $\begin{array}{l}\text { Dois LD de PLA dirigidos } \\
\text { especialmente } \\
\text { adolescentes e publicados } \\
\text { no Brasil: Sempre Amigos: } \\
\text { Português para } \\
\text { estrangeiros; Tudo bem? } \\
\text { Português para uma nova } \\
\text { geração. }\end{array}$ & $\begin{array}{l}\text { Foi detectado um processo } \\
\text { de ruptura do CC nos LD. } \\
\text { Os livros apresentaram uma } \\
\text { forte tendência } \\
\text { metalinguística } \\
\text { desenvolvem } \\
\text { concepção de ensino de } \\
\text { consistente } \\
\text { estruturalista e behaviorista, } \\
\text { sendo assim, uma proposta } \\
\text { distante da comunicativa. }\end{array}$ \\
\hline
\end{tabular}

Na dissertação, Rosa (2015) afirma que, no processo de ensino/aprendizagem, é importante a compreensão pelo aprendiz daquilo que está intrínseco no discurso e que, portanto, o ensino da língua deve ser muito mais do que vocabular e gramatical. Por sua vez, Ricardi (2005) declara como premissa que o ensino de PLA tem como objetivo principal a comunicação adequada do aluno, utilizando o português conforme falado pelas pessoas com quem o aprendiz interage, prestando atenção também na pluralidade do português por todo o país. A autora pretendeu também fornecer, ao professor de PLA, subsídios que o sensibilizem para as contribuições da Sociolinguística, quanto às questões de variação e mudança linguística, proporcionando-o condições de fazer uma melhor escolha dos LD, além de evitar preconceitos linguísticos.

Na tese de doutorado, Pacheco (2006) considerou que o contexto intercultural em que vivem os aprendizes de PLA lhes permite construir um conjunto de experiências e conhecimentos heterogêneos. Para que os aprendizes de língua adicional possam praticar atos de fala em situações de comunicação real com correção e adequação ao 
contexto sociocultural, é de grande importância o desenvolvimento da competência sociocultural. Além da correção gramatical e o respeito à norma culta, a pronúncia e a entonação também interferem no processo do falar bem para os estrangeiros, já que a articulação incorreta dos sons pode criar constrangimentos. A autora também estabeleceu que é importante a interligação entre o componente sociocultural no desenvolvimento de atividades discursivas no processo de ensino/aprendizagem. Há muitas vantagens no desenvolvimento do processo de ensino/aprendizagem voltado para o componente cultural em PLA, já que o professor aprendiz de outra(s) cultura(s) se familiariza com o conteúdo e vocabulário específico de outras áreas e troca experiências com outros profissionais; os alunos, por sua vez, aprendem a língua e a cultura-alvo em situação de uso. A autora ressaltou que ocorre a agilização dos contratos de comunicação com o intercâmbio cultural promovido pela aprendizagem de outra língua e a apreensão de novos rituais de abordagem.

No tocante aos aspectos metodológicos de pesquisa, Rosa (2015) utilizou três critérios de seleção dos livros utilizados em seu trabalho: (1) selecionar discursos de livros destinados a principiantes em Língua Portuguesa; (2) buscar discursos com um conteúdo que poderia ser mais atrativo aos alunos, ou seja, com alguma informação relevante e condizente com a realidade; e (3) os discursos deveriam possuir questões de interpretação, sendo estas, também, objeto de análise da tese.

Os discursos foram analisados sob a perspectiva da Teoria dos Blocos Semânticos (TBS) conforme o seguinte roteiro: "(1) levantar encadeamentos argumentativos que expressem o sentido dos enunciados"; (2) "segmentar o discurso em enunciados"; (3) "relacionar os encadeamentos argumentativos verificando se traduzem sentido do discurso como um todo"; (4) "dar pistas ao leitor sobre a transcrição do material de análise"; (5) "levantar as argumentações internas ao léxico"; (6) "levantar as argumentações internas aos enunciados"; (7) "identificar a importância dos articuladores nos enunciados"; (8) "comparar os discursos por meio das análises realizadas"; e (9) "analisar as questões de interpretação dos discursos a fim de verificar se elas ajudam na compreensão do sentido do discurso" (ROSA, p. 43-44). Além disso, para cumprir com o objetivo do trabalho, após as análises, a autora expôs propostas de interpretação textual, segundo a teoria da argumentação na língua.

O material da análise realizada por Ricardi (2005) consistiu em uma amostragem dos manuais mais utilizados no Centro Federal de Educação Tecnológica do Paraná (CEFET-PR), unidade de Curitiba (Estado do Paraná, Brasil), no período de 2001-2002. 
A autora analisou tanto o exemplar do aluno quanto o do professor, pretendendo observar: (1) "a apresentação do livro"; (2) "a proposta dos autores"; (3) "as concepções de língua e de gramática adotadas"; e (4) "a presença (ou não) de variações linguísticas" (RICARDI, 2005, p. 12). Esclareceu que a atenção foi voltada, especialmente, ao sistema pronominal, devido à diversidade que o caracteriza e à necessidade de estabelecer um recorte para análise.

Pacheco (2006) considerou, como base de análise, a materialidade linguística dos livros selecionados e procurou associar teoria e prática. Além disso, esclareceu que, situada na análise do discurso, a constituição da pesquisa pressupõe a inclusão de recortes variados dos LD. O corpus foi selecionado de forma a se obter um conjunto o mais homogeneizado possível, possibilitando, assim, uma abordagem linguística e também sócio-histórica. Considerando os pressupostos teóricos da pesquisa, definiu o texto na perspectiva plurissemiótica, considerando, assim, o fato de que o texto pode ser multimodal. Foram objeto da pesquisa os três aspectos fundamentais nos contratos de comunicação: identidade, finalidade e circunstâncias.

Antes de iniciar as análises, Rosa (2015) expôs as interpretações dos discursos que foram propostas pelo respectivo $\mathrm{LD}$, assim, o discurso "O trabalho da mulher", por exemplo, trata-se de um texto que informa ao estudante a realidade das mulheres no mercado de trabalho brasileiro com quatro questões de interpretação referentes ao mesmo, que são utilizadas pela autora para análise. A autora concluiu que as questões eram concentradas no conteúdo e, assim, não possibilitavam ao estudante a compreensão semântica do discurso, para tanto, justificou que os exercícios de interpretação devem ter como objetivo ajudar o leitor a entender o discurso como um todo, levando ao leitor à compreensão do que foi lido. Por outro lado, considerou que a questão de múltipla escolha, em que se pede para o aluno escolher um título para o texto lido, interage com a TBS, no sentido que a atividade exige uma compreensão do texto como um todo para que o estudante possa escolher a resposta correta.

Rosa (2015) concluiu que as questões propostas pelos LD se revelaram precárias e, portanto, não eram suficientes para cumprir com seu objetivo. Com isso, a autora apresentou propostas de atividades de interpretação textual baseadas na Teoria da Argumentação na Língua. Para tanto, justificou que estas propostas foram para demonstrar que, com atividades adequadas, pode-se possibilitar ao estudante um melhor aprendizado por meio da reflexão e compreensão do texto como um todo. 
Já Ricardi (2005) manifestou a necessidade da colaboração de sociolinguistas na elaboração dos materiais didáticos e, além disso, que os professores devem ter condições de oferecer um ensino com muito mais qualidade, apresentando o português brasileiro como uma língua heterogênea que oferece variadas possibilidades de dizer. Ainda, julgou haver alguns aspectos e tópicos relevantes do trabalho que mereceriam um desdobramento, como: (1) "examinar outras facetas do sistema pronominal (clíticos, possessivos)"; (2) "levantar os tempo-modos verbais trabalhados nos materiais didáticos"; (3) "analisar os pronomes relativos apresentados aos alunos"; (4) "averiguar o uso de conectores diversos, entre outros" (RICARDI, 2005, p. 104-105). A autora considerou que seria importante elaborar, em uma proposta mais voltada à prática pedagógica e a título de sugestões metodológicas, uma série de atividades que abrangessem, com atenção à questão do preconceito, aspectos da variação e mudança linguística.

Com a análise, Pacheco (2006) verificou propostas em que não era especificado o gênero que o aluno deveria produzir e, portanto, as classificou na categoria indefinida, sendo que encontrou, nos LD, uma maioria de atividades escritas, assim, considerou implementada no material uma visão grafocêntrica. Argumentou que esse é um aspecto negativo já que os adolescentes preferem a oralidade nas atividades escolares, portanto, deveria ter uma grande diversidade de propostas de produção textual. Defendeu ainda que é relevante aos estudantes de PLA o contato com textos orais para que eles possam compreender aspectos típicos da produção oral, como marcadores conversacionais e hesitações.

Com relação à forma de realização das atividades de produção textual propostas, verificou que a maioria era individual. A autora também descreveu que era proposta a produção de vários gêneros textuais, porém considerou que não era explicitado o contexto discursivo e, além disso, não eram estabelecidas as condições de produção de determinado gênero textual. Em relação aos textos apresentados nos livros, a autora verificou três tipos: (1) os produzidos especialmente para o livro com a intenção do ensino das expressões e das regras gramaticais da língua (incluindo as expressões idiomáticas); (2) os adaptados, ou seja, aqueles baseados em textos 'autênticos' retirados de veículos de comunicação, e produzidos para que pudessem atender aos interesses didáticos da unidade de ensino onde seriam inseridos; (3) e os textos 'reproduzidos na íntegra', ou seja, aqueles em que mantiveram todas as características da fala original, em caso de texto oral, e incluído os textos na íntegra, em caso de textos escritos (PACHECO, 2006). 
Como característico das pesquisas em Linguística Aplicada, Pacheco (2006) propôs uma atividade de desenvolvimento da linguagem oral, a qual denominou de Clube da Leitura, inspirada no conceito de leitura do mundo de Paulo Freire. Justificou que é uma atividade muito eficaz em turmas de nível avançado, assim como é também muito boa quando desenvolvida em turmas de nível intermediário e até de iniciantes, conforme as especificidades de cada grupo. Corresponde a uma atividade diária, realizada nos primeiros minutos de cada aula, em que os alunos são convidados a fazerem uma resenha crítica de suas experiências culturais e também uma análise dos principais acontecimentos atuais, no Brasil e no mundo. $\mathrm{O}$ aluno pode também ilustrar sua apresentação com textos de revistas, jornais, entre outros veículos de comunicação, utilizando os recursos da sala de aula, TV, vídeo, retroprojetor ou computador. Da mesma forma, a autora relatou que as aulas de falar sobre a família, a cidade (país) onde os alunos moravam e os hábitos de seus moradores, podem ser também ilustradas através de fotos e apresentadas para a turma utilizando retroprojetor, além disso, podem também ser utilizados blogs em que poderão ser discutidas e comentadas as marcas de identidade, inclusive as características culturais.

Finalmente, diante dos aspectos culturais, Pacheco (2006) percebeu uma pretensão de posicionamento neutro, principalmente referente às imagens inseridas, já que possibilitavam ao aprendiz estrangeiro pouca assimilação da realidade cultural brasileira e, inclusive, identificou algumas imagens que retratavam uma realidade inexistente no Brasil. Constatou que há necessidade de se atentar ao papel da imagem na produção do LD. O ensino da língua adicional requer também o desenvolvimento de práticas discursivas que possibilitam ao aluno a capacidade de ler imagens, refletir e identificar nelas efeitos de sentido que caracterizam a língua/cultura-alvo.

\section{CONSIDERAÇÕES FINAIS}

Os LD possibilitaram diferentes enfoques investigativos, construídos a partir de interesses interdependentes, aqui identificados como práticos ou teóricos. Os primeiros correspondem aos aspectos linguístico-pedagógicos que interferem mais diretamente na elaboração ou no uso do MD, a exemplo das funções exercidas pelas imagens e da adequação da linguagem verbal utilizadas nos livros, bem como das abordagens ou metodologias de ensino assumidas. Os segundos correspondem ao que denominamos de pesquisas de aplicação de teorias linguísticas de referência, caracterizadas pela análise crítica de apropriações teóricas nos MD. 
Além da análise dos LD como documentos, as pesquisas das dissertações e tese se utilizaram de diferentes instrumentos de geração de dados, contribuindo para a complexificação do objeto de pesquisa construído a partir do cruzamento de dados. Alguns dos instrumentos utilizados foram questionários e entrevistas com professores e alunos colaboradores ou participantes. Considerando que alguns trabalhos apresentaram encaminhamentos ou propostas de materiais para aulas de PLA, conforme movimento investigativo característico da Linguística Aplicada (cf. CAVALCANTI, 1986), foram realizadas intervenções pedagógicas para testagem de MD.

A análise das pesquisas revelou a relevância do referido material no ensino de português para falantes de outras línguas. Em nenhum dos trabalhos investigados, os autores defenderam o abandono do referido material no ensino. As pesquisas mostraram a necessidade da melhora da qualidade dos LD, o que demanda investimentos dos produtores e, inclusive, contribuições acadêmicas no tocante à produção de conhecimentos para orientar a produção e o uso dos LD em contextos de instrução.

O ensino de PLA continua se configurando como uma área fértil de pesquisas, especialmente no campo investigativo da Linguística Aplicada. Por fim, salientamos que não são numerosos os trabalhos acadêmicos nesse campo, especialmente no tocante às demandas particulares emergentes a partir do aprendizado da língua e da cultura brasileira por aprendizes de nacionalidades específicas.

\section{LISTA DE DISSERTAÇÕES E TESE ANALISADAS}

CASTRO, G. P. O. A abordagem subjacente ao material didático de Português língua estrangeira: a análise da Multimodalidade textual. Dissertação (Mestrado em Linguística Aplicada) - Brasília. Departamento de Línguas Estrangeiras e Tradução, Universidade de Brasília, 2009. $81 \mathrm{f}$.

CUICUI, C. A seleção e a produção de materiais didáticos no processo do ensino do português aos alunos chineses. (Dissertação de Mestre em Ensino do Português como Língua segunda e Estrangeira) - Lisboa. Faculdade de Ciências Sociais e Humanas da Universidade Nova de Lisboa, 2012. 69 f.

GONZALÉZ, V. A. Análise de abordagem de material didático para o ensino de línguas (PLE/PL2). Dissertação (Mestrado em Linguística Aplicada) - Brasília. Departamento de Línguas Estrangeiras e Tradução, Universidade de Brasília, 2015. 170 f. 
MENDES, K. A. Português língua estrangeira: uma análise do livro didático. Dissertação (Mestrado em Letras e Linguística) - Instituto de Letras, Universidade Federal da Bahia. Salvador, 2006. 69 f.

PACHECO, Denise Gomes Leal da Cruz. Português para estrangeiros e os materiais didáticos: um olhar discursivo. Tese (Doutorado em Letras Vernáculas) - Universidade Federal do Rio de Janeiro, Instituto de Letras, Rio de Janeiro, 2006. 335 f.

RICARDI, D. A diversidade linguística brasileira no material didático para o ensino de português para estrangeiros. Dissertação (Mestrado em Linguística) - Universidade Federal de Santa Catarina, Florianópolis, 2005. 130 f.

ROSA, G. P. S. O sentido construído pelo discurso no ensino de língua portuguesa como língua estrangeira. Dissertação (Mestrado) - Faculdade de Letras, Pontifícia Universidade Católica do Rio Grande do Sul, Porto Alegre, 2015. 68 f.

STERNFELD, L. Aprender português-língua estrangeira em ambiente de estudos sobre o Brasil: a produção de um material. Dissertação (Mestrado em Linguística Aplicada) Instituto de Estudos da Linguagem, UNICAMP, 1996. 236 f.

VAZ, C. M. Tintim por tintim: um material didático de português para falantes de espanhol com foco nas expressões idiomáticas. Dissertação (Mestrado em Linguística Aplicada) - Universidade de Brasília, Brasília, 2013. 137 f.

\section{REFERÊNCIAS}

ALMEIDA FILHO, J. C. P. O ensino de português para estrangeiros nas universidades brasileiras. In: José C. P. de Almeida Filho; Leonor Lombello (Orgs.). Identidade e caminhos no ensino de português para estrangeiros. Campinas: Pontes/Editora da Unicamp, 1992, p. 11-16.

CARVALHO, S. da C. Políticas de promoção internacional da língua portuguesa: ações na América Latina. Trabalhos em Linguística Aplicada. Campinas: Unicamp, 2012, v. 51, n. 2, pp. 459-484.

CAVALCANTI, M. C. A propósito de Linguística Aplicada. Trabalhos em Linguística Aplicada. Campinas: Unicamp, n. 7, p. 05-12, 1986.

BOHN, H. I. Avaliação de materiais. In: BOHN, H. I.; VANDRESEN, P. (Org.) Tópicos de Linguística Aplicada: o ensino de línguas estrangeiras. Florianópolis: UFSC, 1988.

DINIZ, L. R. A. Política linguística do estado brasileiro para a divulgação do português em países de língua oficial espanhola. Trabalhos em Linguística Aplicada. Campinas: Unicamp, 2012, v. 51, n. 2, p. 435-458. 
OLIVEIRA, G. M. Política linguística e internacionalização: a língua portuguesa no mundo globalizado do século XXI. Trabalhos em Linguística Aplicada. Campinas: Unicamp, 2013, v. 52, n. 2,p p. 409-433.

SILVA, W. R.; ELGEBALY, M. T. M. A.; MEDEIROS, Ana L. Pelo ensino do português brasileiro como língua adicional no Egito. Gragoatá. Niterói: UFF, 2017. (submetido) 